\title{
EFFECT OF PASSENGERS' FLOWS ON REGULARITY OF METRO SERVICES: CASE STUDIES OF ROME LINES A AND B
}

\author{
MARCO ANTOGNOLI, FRANCESCO GIROLAMI, STEFANO RICCI, LUCA RIZZETTO \\ DICEA, Sapienza Università di Roma, Italy
}

\begin{abstract}
The regularity is a key performance in the operation of a metro service, because it is normally affecting a large set of secondary performances: for example, punctuality, energy efficiency, economic efficiency and vehicles availability.

Human behaviours are affecting the regularity by introducing deviations between planned and actual times in various operational phases of metro services: for example, dwelling times, acceleration/deceleration times, inversion times at terminus and headways themselves.

The variability in passengers' flows is one of the most relevant parameters affecting mainly dwelling times and finally headways themselves.

In this framework, this article is specifically presenting the results of experimental surveys on metro services operating in Rome (lines A and B).

On these lines, a systematic counting of passengers boarding and alighting in the most crowded stations, combined with simultaneous measurement of actual dwelling times and headways, has been performed.

The collected results have been analysed, cleaned by inconsistent data and statistically interrelated looking for significant trends to compare with the most consolidated theoretical models and to quantify the effects in line with the literature developments, including those by the authors themselves.

Finally, the focus is on the most relevant quantitative outputs and the mainly identified and outlined further research needs.
\end{abstract}

Keywords: behaviours, metro, punctuality, railways, reliability, transport

\section{INTRODUCTION}

The regularity represents a key performance in the operation of a metro service, because it is normally affecting a large set of secondary performances: for example, punctuality, energy efficiency, economic efficiency, infrastructures and vehicles availability.

Human behaviours, as largely recognized in various studies [1-4], are directly or indirectly affecting the regularity, by introducing deviations between planned and actual times in various operational phases of metro services: for example, dwelling times, acceleration/deceleration times, inversion times at terminus, headways themselves.

In the literature, it is also recognized $[5,6]$ that the variability in passengers' flows is one of the most relevant parameters affecting mainly dwelling times and finally headways themselves.

Therefore, an ongoing research activity at the Department of Civil, Building and Environmental Engineering of Sapienza University of Rome is approaching with combined experimental and theoretical methods the problem to clarify the concerned dependence and quantify it according to various operational contexts.

In this framework, this article reports the results of field observations, carried out in some stations on lines A and B of the Rome metro. The purpose of these surveys was to detect some key operational aspects: the number of passengers alighting, boarding the trains and actual times of train arrival and closing the doors. 


\section{METHODOLOGY OF SURVEYS}

The survey team includes three people in ten stations, equally distributed between lines A and B of the Roman metro network (Table 1).

All the selected stations represent interchange nodes: Anagnina, Termini, Cornelia, Ponte Mammolo, Tiburtina, Piramide and Laurentina with bus network; Valle Aurelia with an urban railway; Tiburtina, Termini and Piramide with both regional and long distance railways; moreover, Termini is the interchange station between lines A and B of metro network (Fig. 1).

The surveys took place in several weekdays during the $2 \mathrm{~h}$ peak period (8:00-10:00) in June-July 2016.

Table 1: Stations where surveys took place.

\begin{tabular}{ll}
\hline Line A & Line B \\
\hline Anagnina & Ponte Mammolo \\
San Giovanni & Tiburtina \\
Termini & Termini \\
Valle Aurelia & Piramide \\
Cornelia & Laurentina \\
\hline
\end{tabular}

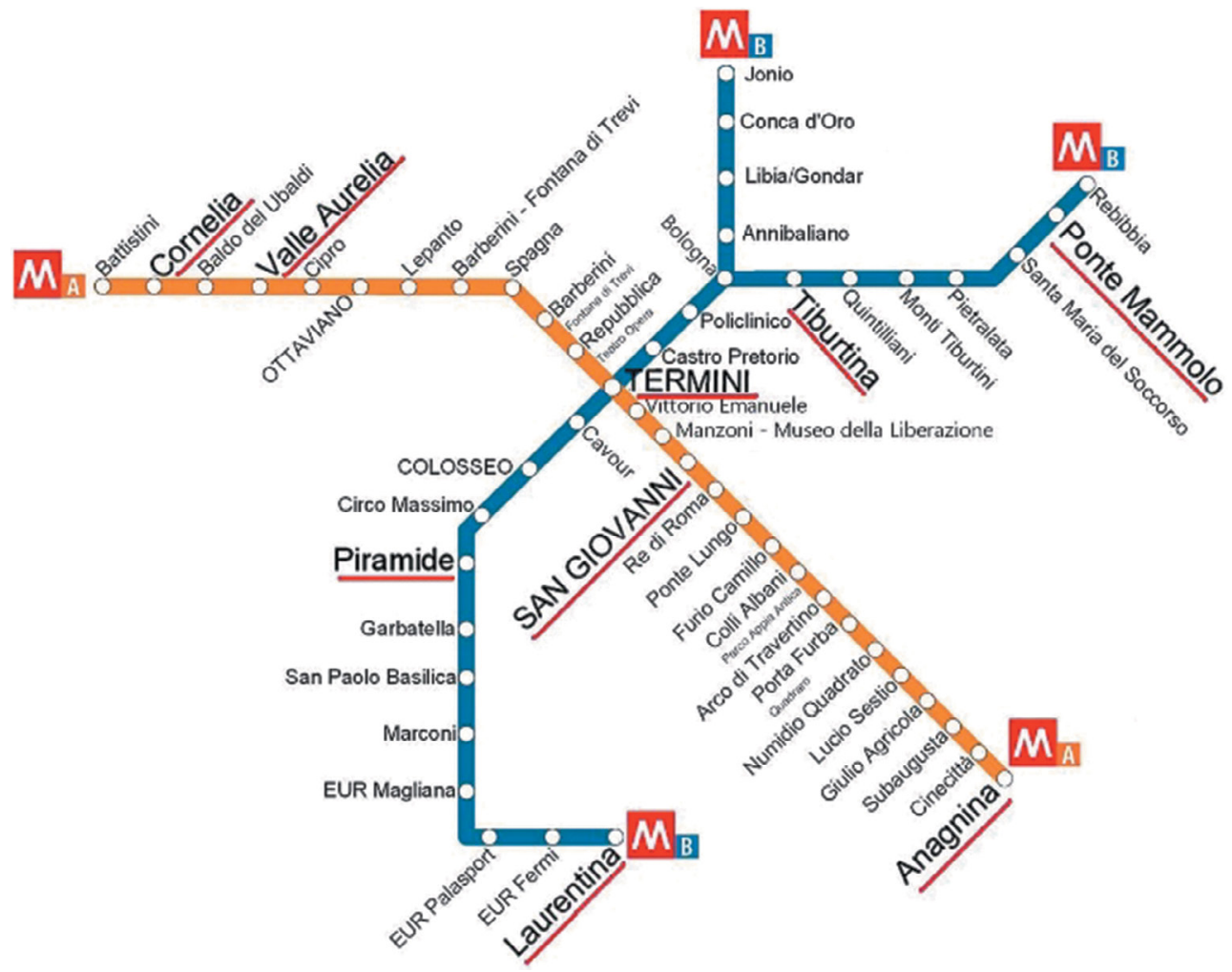

Figure 1: Scheme of A and B metro lines and investigated stations. 
Before proceeding with the survey observations, inspection in various stations allows to detect their characteristics in terms of number and location of entries/exits, the presence of elevators, escalators, as well as the actual movements of the passengers, who sometimes do not respect the specializations of the platforms access.

During the surveys, the acquired data were:

- time of train arrival;

- time of door opening;

- number of people getting off the train;

- number of people getting on the train.

Normally, during the surveys, two observers stood at the entrance and the exit of the platform, and the third one noted the intervals between train arrivals and doors opening and supported the observer standing in the most crowded area.

For stations with more than two accesses and affected by major passenger flows, the missing counting was surrogated by interpolation.

It was the case of Termini station on line A, where the main problem is passengers' flows mix in areas between the two platforms (Fig. 2).

The observations show that, in the investigated period, incoming passenger flows remain almost constant for about $30 \mathrm{~min}$, which allows calculating rather stable average flow rates of incoming passengers.

The calculation is based on the following procedure:

a) During the 5 min before each 30 min period $(7: 55 ; 8: 25 ; 8: 55 ; 9: 25)$, the observers, placed in the hallway leading to the platforms (direction of Battistini and Anagnina), count all the persons on the way to the access.

b) On the first day, observers count the passengers to Anagnina only.

c) On the following days, the calculation of passengers to Battistini is by subtracting the flows to Anagnina of the previous day from the total incoming flow.

The estimation for Termini line B station is based on a similar process, with five passengers accessing the platforms in one direction (Fig. 3).

\section{TERMINI (LINE A)}

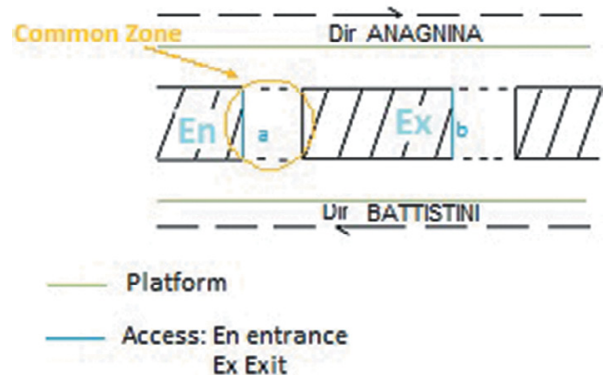

Figure 2: Termini Line A. Layout of entrance and exit to/from the platforms. 


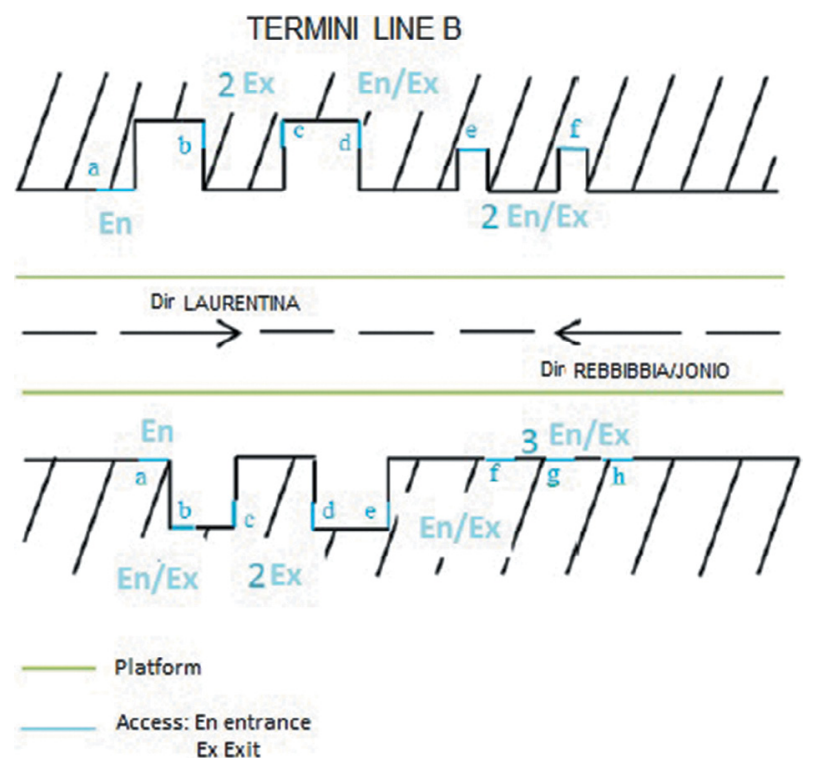

Figure 3: Termini Line B. Layout of entrance and exit to/from the platforms.

\section{COLLECTED DATA}

As an example of data collected according to the methodology mentioned earlier, the flows of incoming and outgoing passengers detected for some stations are in the following paragraphs:

Line A: San Giovanni (in the direction of Battistini) and Termini (in the direction of Anagnina)Line B: Tiburtina (in the direction of Laurentina) and Piramide (in the direction of Jonio/Rebibbia)

\subsection{Passengers' flows on Line A: San Giovanni}

In San Giovanni (in the direction of Battistini), high flows are especially incoming but the outgoing component is not negligible, especially for the time bands between 8:30 and 9:30 (Fig. 4).

\subsection{Passengers' flows on line A: Termini}

Termini is the main interchange node of the Roman transport network, connected with both regional and long-distance railway lines, metro line B and several buses and tram lines.

The flows reflect this situation: they always remain high and substantially balanced between incoming and outgoing (Fig. 5).

\subsection{Passengers' flows on line B: Tiburtina}

Tiburtina is the second railway station in Rome, interchanges with urban buses as well as with long-distance buses. The incoming flows are predominant over those outgoing and the trend shows four peaks, observable, albeit with less intensity in the pattern of outgoing flows (Fig. 6). 


\section{San Giovanni dir Battistini}

In/out flow

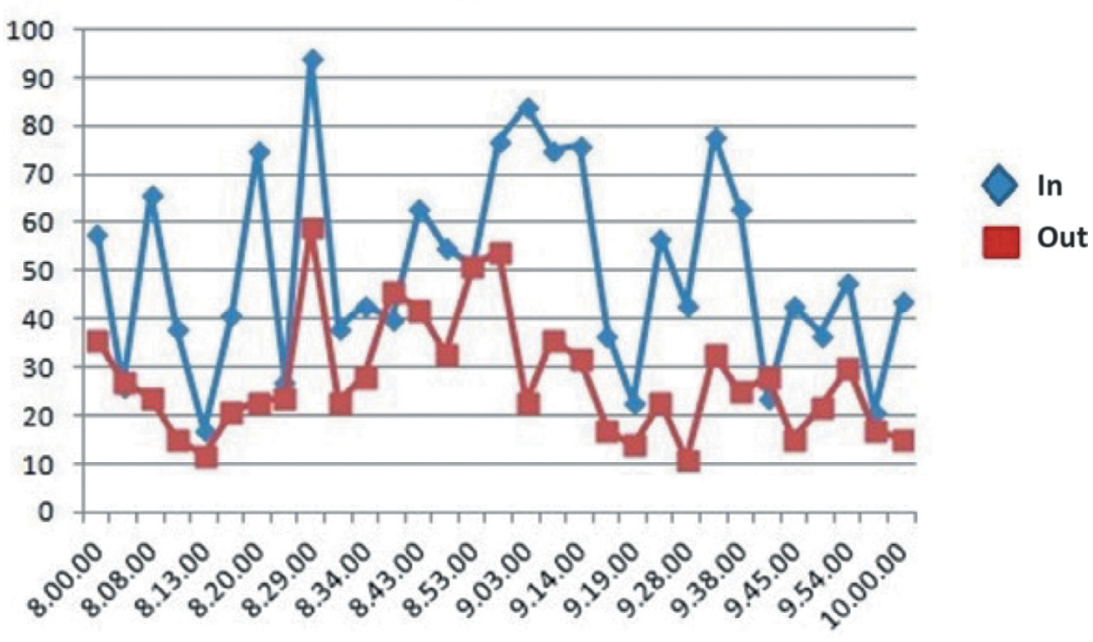

Figure 4: Line A. Incoming and outgoing flows observed in San Giovanni station (in the direction of Battistini).

\section{Termini line A dir Anagnina In/out flow}

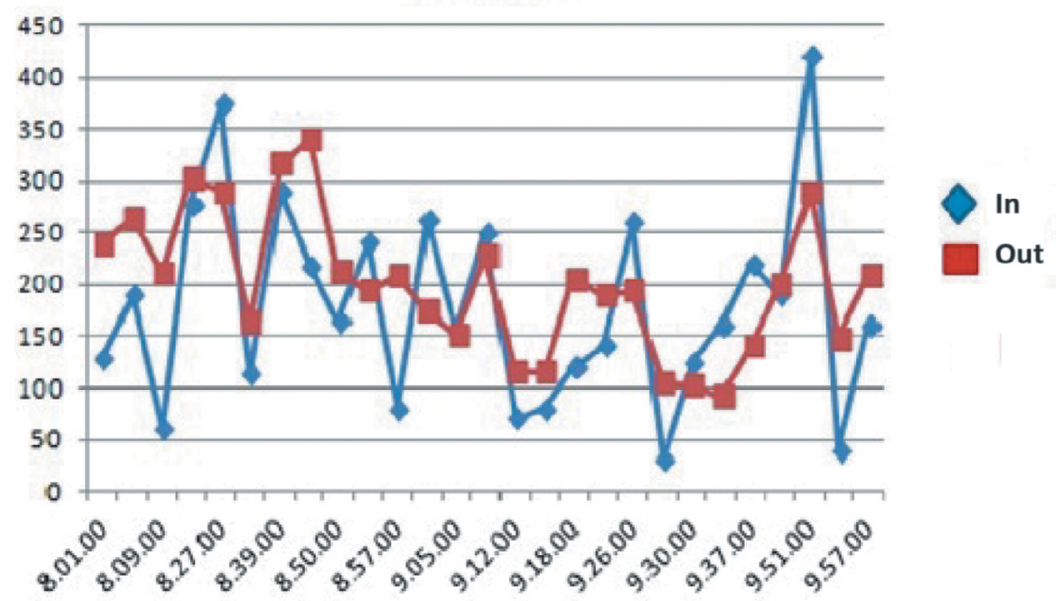

Figure 5: Line A. Incoming and outgoing flows observed in Termini station (in the direction of Anagnina). 


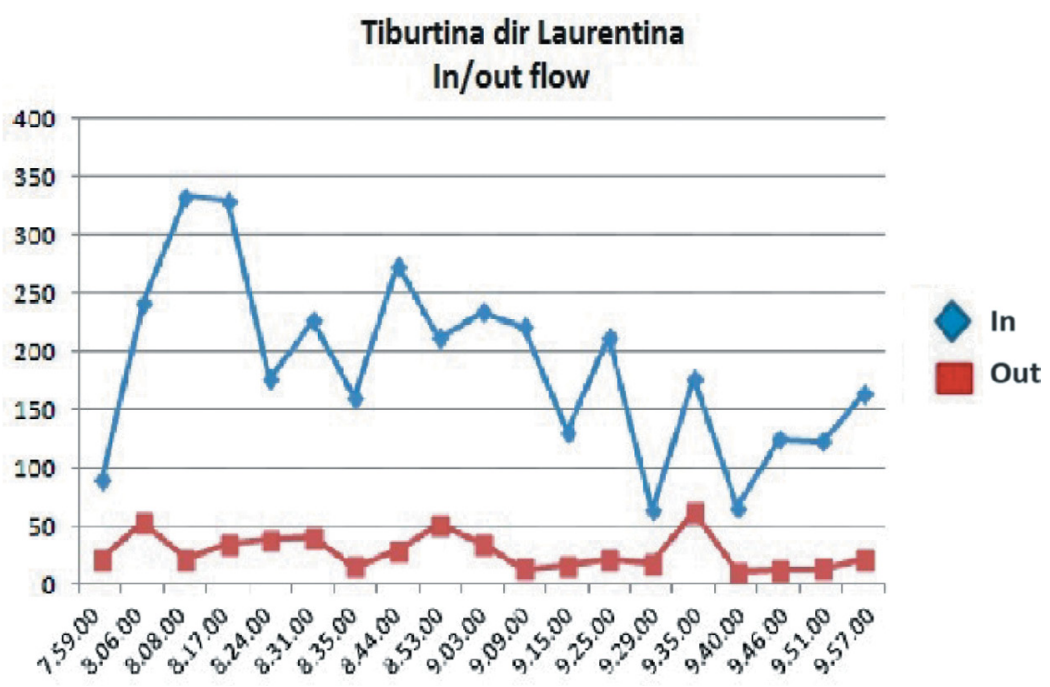

Figure 6: Line B. Incoming and outgoing flows observed in Tiburtina station (in the direction of Laurentina).

\subsection{Passengers' flows on line B: Piramide}

Piramide (in the direction of Jonio/Rebibbia) experiences very high incoming flows (Fig. 7), being an important interchange with the regional railways, with a self-evident peak in the time slot 8:15-8:45.

\subsection{Dwell time}

In addition to the passengers' flows, the survey detected the dwell time of trains in the stations too. Table 2 shows the average dwell time calculated from the measured values in each station.

\section{Piramide dir Jonio/Rebibbia In/out flow}

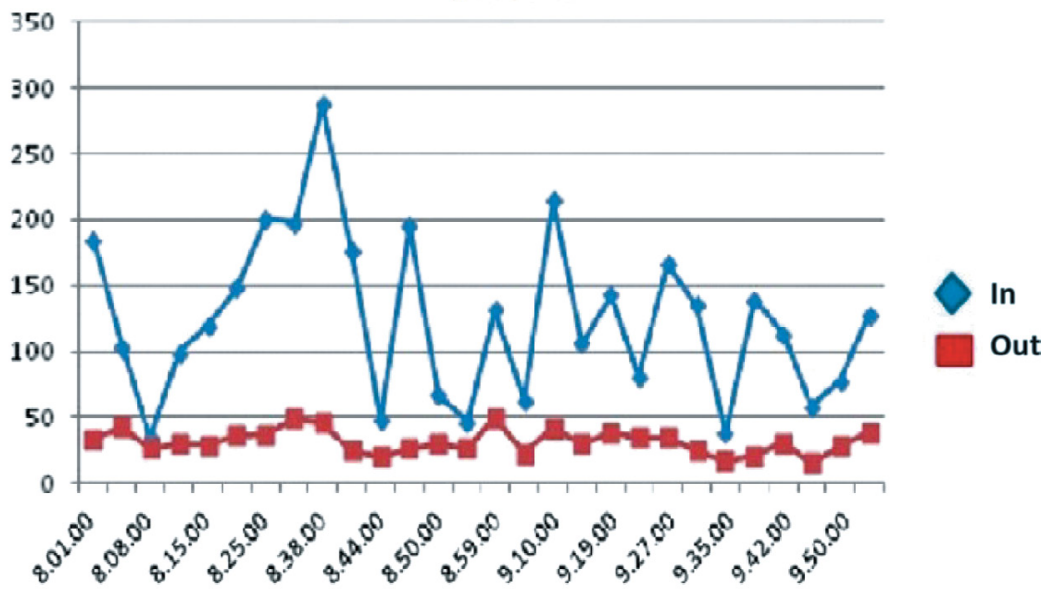

Figure 7: Line B. Incoming and outgoing flows observed in Piramide station (in the direction of Jonio/Rebibbia). 
Table 2: Average values of measured dwell times.

\begin{tabular}{llc}
\hline Lines & Stations & Average dwell time $(s)$ \\
\hline A & Anagnina & 18.40 \\
& San Giovanni & 14.95 \\
& Termini & 42.86 \\
& Valle Aurelia & 14.04 \\
& Cornelia & 12.98 \\
B & Laurentina & 36.02 \\
& Piramide & 25.65 \\
& Termini & 35.18 \\
& Tiburtina & 25.56 \\
& Ponte Mammolo & 15.48 \\
\hline
\end{tabular}

\section{CORRELATION BETWEEN DWELL TIMES AND FLOWS}

After the data collection, the focus was on the search of a relationship between passenger's flows and dwell times.

Figure 8 represents the dwell times versus total flows, obtained by summing up all the incoming and exiting passengers for each investigated station on both lines: the area between the two red lines seems to show a possible correlation.

Nevertheless, beside it, some points indicate significantly longer dwell times, despite the rather low flows (yellow area), possibly representing irregularities due to congestion or traffic regulation measures.

Figures 9 and 10 describe the correlation between dwell times and flows, separately for lines A and B, obtained by eliminating the points included in the yellow area in Fig. 8 .

Line A as a whole (Fig. 9) presents a strong correlation between dwell times and flows, with $R^{2} \approx 0.80$, expressing that the linear dependence is well representing the phenomenon.

Regarding line $\mathrm{B}$, the trend is more irregular and confirmed by the significantly lower value of $R^{2} \approx 0.51$ (Fig. 10).

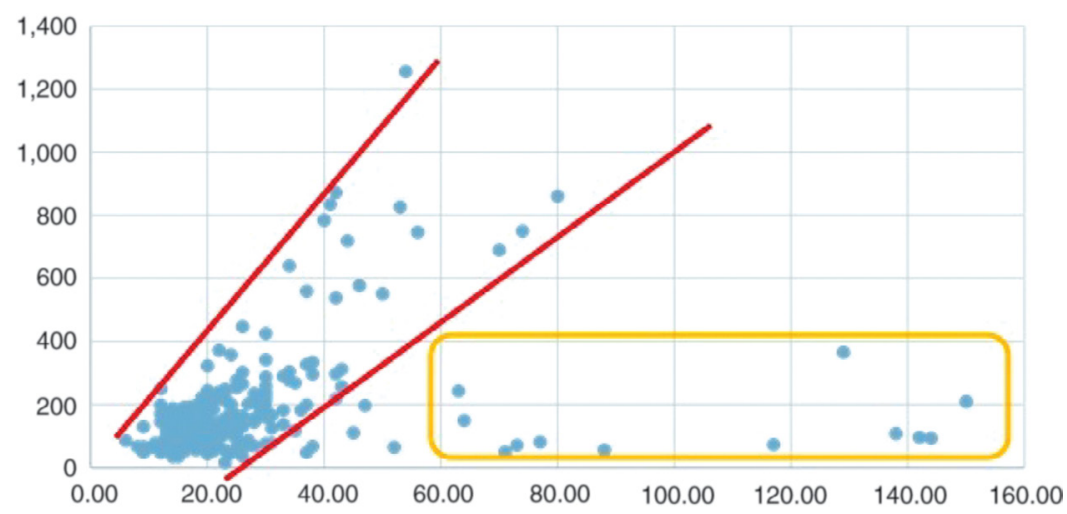

Figure 8: Dwell times (s) versus passengers' flows in all investigated stations. 


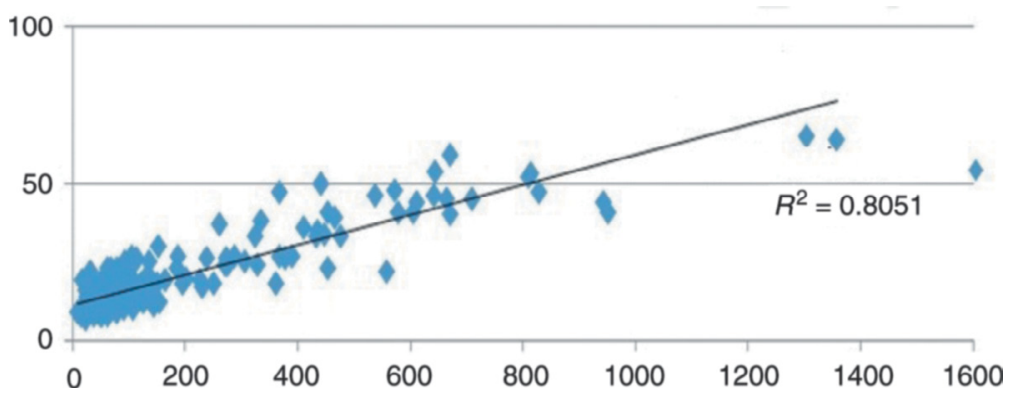

Figure 9: Dwell times (s) versus passengers' flows in line A stations.

It seems to be the result of a systematic wide dispersion of data concerning the stations in the direction Jonio/Rebibbia, while in the direction Laurentina the dispersion is lower.

The most interesting feedback is anyway in the average alighting + boarding rate, which is almost similar for both lines: about 15 passengers (incoming + outgoing) per second of dwell time.

It seems realistic when compared with an estimated maximum exchange rate per train around 48 passengers/s ( 2 passengers/s/door $\times 24$ doors).

The greater dispersion in the direction of Jonio/Rebibbia might be because line B in this direction operates with branched unbalanced services towards Jonio and Rebibbia terminuses.

The consequence is that the intervals are also unbalanced and, consequently, the passengers' amount on platforms may vary significantly.

Finally, by examining the distributions for single stations, the dependence between passengers' flows and dwell times is decreasing with the entity of the flows themselves.

Exemplificative cases are:

Laurentina station on line B (Fig. 11), terminus of the line itself, which presents a substantial independence between dwell times (mainly depending on inversion manoeuvres) and flows (moderate due to the extremal location of the station and limited interchange function);

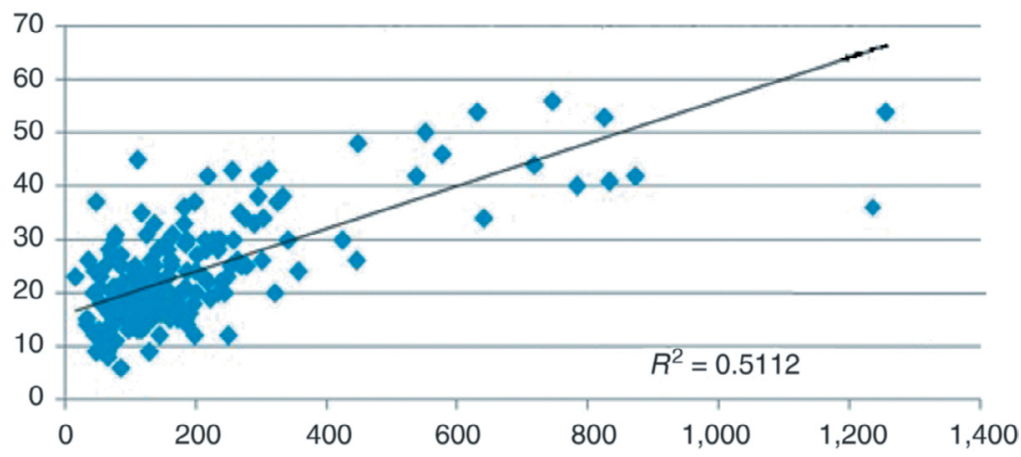

Figure 10: Dwell times (s) versus passengers' flows in line B stations. 
Termini station on line A, in the direction of Anagnina (Fig. 12), key interchange station of the network, which shows a strict dependence between dwell times (the longest) and flows (the largest).

\section{CONCLUSIONS}

The first analyses on the collected data have generally confirmed the relevant dependence upon the passengers' flows of the dwell time around an almost consolidated average value of about 15 passengers/s.

However, the relationship between the two quantities is more evident in stations affected by relevant flows.

Whenever the flows decreass, the link becomes more labile until it appears almost independent upon it, due to the increasing role of operational constraints and traffic regulation issues (e.g. in Laurentina, line B terminus station).

Moreover, the greater dispersion systematically recorded in the dwell time of stations in the direction of Jonio/Rebibbia of line B, seems to depend on the presence of unbalanced branching operation.

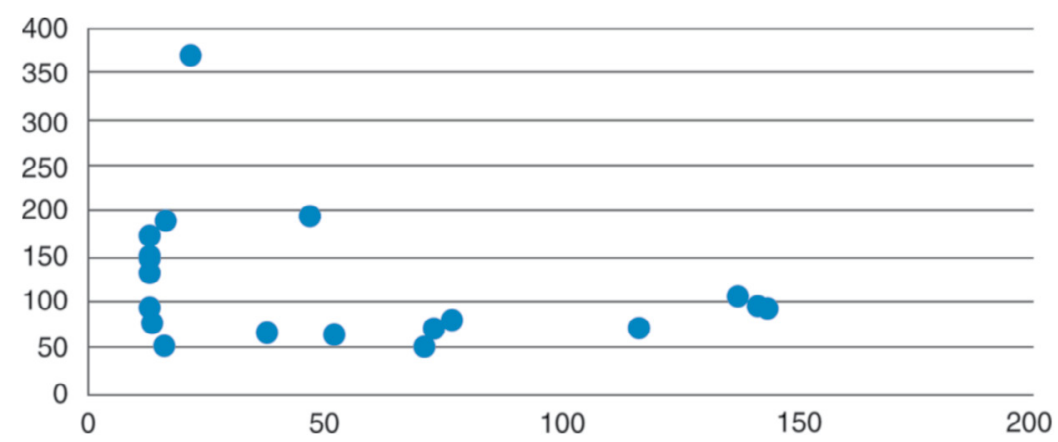

Figure 11: Dwell times (s) versus passengers' flows in Laurentina station (line B).

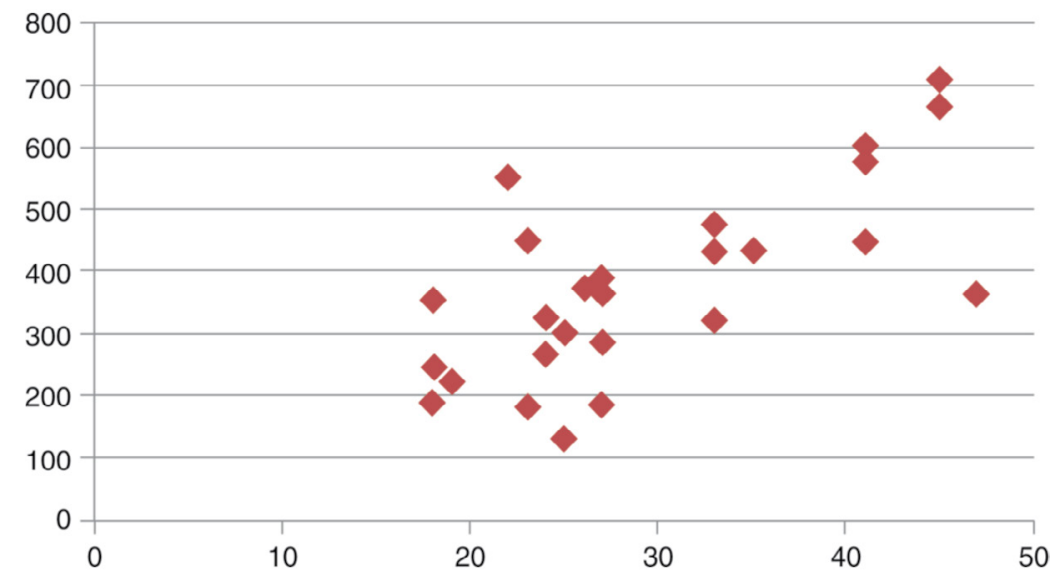

Figure 12: Dwell times (s) versus passengers' flows in Termini station (line A). 
The average dwell times resulting from the survey deviate sometimes significantly from the theoretical average values considered in the scheduling process, which introduces random components and systematic disturbances in the headway, worsening the operation regularity.

Further research developments will consist both in:

- Extension of surveys in time (longer periods) and space (more stations), to investigate specifically the combination of passengers' flows and other operational factors towards the identification of a possible natural trade-off between them;

- Cross-analysis with automatically recorded operational data to investigate and identify the most relevant lines' features capable of affecting the identified dependences (e.g. unbalance between branched services revealed by the survey results for line B in the Jonio/ Rebibbia direction).

\section{ACKNOWLEDGEMENTS}

The authors acknowledge the relevant contribution to the survey given by students Jean Philippe Liaubet and Safia Lif, during their curricular stage at Sapienza University of Rome in 2016.

\section{REFERENCES}

[1] Dicembre, A., Nanni, C., Ricci, S. \& Sorace, F., Automation of high density metro lines: Rome line A case study. 13th International Conference APM-ATS Automated People Movers \& Transit Systems, Paris, 2011.

[2] Malavasi, G., Palleschi, P. \& Ricci, S., Driving and operation strategies for tractionenergy saving in mass rapid transit systems. Proceedings of the Institution of Mechanical Engineers, Part F: Journal of Rail and Rapid Transit, 225(5), pp. 475-482, 2011. DOI: 10.1177/2041301710395077.

[3] Nash, A. \& Huerlimann, D., Railroad simulation using OpenTrack. Computers in Railways IX, WIT Press, Southampton, 2004.

[4] Sansò, B. \& Girard, P., Instantaneous power peak reduction and train scheduling desynchronization in subway systems. Transportation Science, 31(4), pp. 312-323, 1997. DOI: $10.1287 /$ trsc.31.4.312.

[5] Antognoli, M., Malavasi, G. \& Ricci, S., Operation automation level in an underground line and service reliability. 1st International Seminar on Railway Operations Modelling and Analysis RailDelft2005, 2005.

[6] Harris, N.G. \& Anderson, R.J., An international comparison of urban rail boarding and alighting rates. Proceedings of the Institution of Mechanical Engineers, Part F: Journal of Rail and Rapid Transit, 221, pp. 521-526, 2007. DOI: 10.1243/09544097JRRT115. 